\title{
Rainfall variability from a dense rain gauge network in north-western Italy
}

\author{
A. Baronetti ${ }^{1, *}$, F. Acquaotta ${ }^{1,2}$, S. Fratianni ${ }^{1,2}$ \\ ${ }^{1}$ Department Earth Sciences, and ${ }^{2}$ Centro Interdipartimentale sui Rischi Naturali in Ambiente Montano e Collinare, \\ University of Turin, 10125 Turin, Italy
}

\begin{abstract}
The aim of this study was to investigate the spatial and temporal distribution of rainfall in Piedmont, a region in north-western Italy, in order to evaluate the high intensity precipitation events that occurred in the 2004-2016 period. A daily precipitation series of 211 ground stations, belonging to 2 different meteorological monitoring networks, were analysed. As at first step, a quality control was performed on the daily precipitation series to evaluate the homogeneity of the series. The annual rainfall events were spatialised, using the ordinary kriging method, considering the whole set of weather stations. Moreover, 5 climatic areas were identified through a cluster analysis method. In order to better understand the extreme rainfall events, the main climatic precipitation indices were calculated, using ClimPACT2 software, and the thresholds by percentile were calculated for each cluster on a daily scale to identify the different precipitation types (weak, medium, heavy, very heavy [R95p]). Non-parametric (Kolmogorov-Smirnov and Wilcoxon) and parametric (Student's $t$-test) tests were applied to the annual and seasonal number of events observed for each rainfall class in order to study the statistical relationship between the clusters. The results lead to the conclusion that the investigated area is characterised by an increase in precipitation. Considering the extreme events, this methodology shows that even though the north sector is the wettest, central Piedmont is the area in which the highest number of extreme events was recorded.
\end{abstract}

KEY WORDS: Piedmont $\cdot$ Rainfall $\cdot$ Extreme events $\cdot$ Kriging $\cdot$ Cluster analysis Resale or republication not permitted without written consent of the publisher

\section{INTRODUCTION}

Climate change is part of the natural 'life cycle' of our planet. In the history of the Earth, the climate has changed many times, even in a radical way. Much of the climate change that has been observed since 1950 has not only been dictated by natural causes, but also by human activities. In fact, many of these activities, which are mainly based on the exploitation of carbon and its derivatives, have had a strong and irreversible impact on global ecosystems (terrestrial, marine, freshwater) (IPCC 2014a). In the last few years, the Mediterranean region has been affected a great deal by climate change (Drobinski et al. 2016). Owing to the specific characteristics of this region, climate change may have a wide-ranging impact that could affect the socio-economic and production sec- tors as well as the environment (e.g. Fazzini et al. 2004, Davis \& Hanna 2016). The effects of climate change are not only the result of a decrease in the total rainfall amount. In this regard, the increasing long periods without precipitation during the rainiest season, which have led to desertification in some areas in the world, are of particular interest (IPCC 2014b). For this reason, rainfall changes are widely recognised as an important factor in the control of environmental processes (Meersmans et al. 2016). In fact, it has been recognised that changes in precipitation patterns can have important financial, social and ecological consequences. In the Mediterranean region, these changes are a response to the climate change that took place in the 20th century (Queralt et al. 2009). However, observations of precipitation changes as a result of climate change remain un- 
clear. As stated by the IPCC (2013), 'confidence in precipitation changes averaged over global land areas since 1901 was low prior to 1951 and medium afterwards' (Scherrer et al. 2016). The study of precipitation events and their frequency is very important for understanding why they happen, and for determining whether there are any signs or periodicities (Boccolari \& Malmusi 2013). In this context, the IPCC introduced a Special Report on Extreme Events (SREX) in which the main extreme events of relevance to society and ecosystems were registered in order to study the relationship between climate extremes and their impacts (Skansi et al. 2013). Moreover, the Expert Team on Climate Change Detection and Indices (ETCCDI) developed a set of climate change indices to facilitate the investigation of extreme temperature and precipitation events (Kharin et al. 2013). The development of the indices includes a free user-friendly software package written in R (ClimPACT2) and a website that has been developed to describe all the indices, the quality control procedures and references to relevant literature (Sillmann et al. 2013).

Several efforts have been devoted to the study of extreme rainfall events, and trends of these events have been obtained for southern and central America (Haylock et al. 2006, Zandonadi et al. 2016), Canada (Zhang et al. 2001), Japan (Iwashima \& Yamamoto 1993) and Europe (Vicente-Serrano et al. 2010, Piccarreta et al. 2013). Several studies conducted on the rainfall trend in the Mediterranean area have shown conflicting results. Toreti et al. (2009) reported a decrease in the total precipitation in Italy. In fact, a reduction of about 10 to $20 \%$ was observed during the 1951-1995 period, with southern Italy showing a reduction of about $26 \%$. Over a synchronous but longer period (1952-2002), Ciccarelli et al. (2008) showed no significant rainfall trends in northern Italy. Brunetti et al. (2004) indicated an increase in the period without wet days per year, which they linked to more intense precipitations, while the research of Boccolari \& Malmusi (2013) showed a large increment in the rainfall amount. As far as the frequency of extreme wet events is concerned, Alpert et al. (2002) highlighted an increase in heavy and extremely heavy events (exceeding $128 \mathrm{~mm} \mathrm{~d}^{-1}$ ) in Italy. On the other hand, Rodrigo (2010) showed a constant or decreasing number of extreme events. Over the last $50 \mathrm{yr}$ or so, a tendency towards a decrease in number of rainy days and an increase in intensity has been found in Piedmont. Moreover, a significant increase in the number of events falling into the highest class-interval (comprising events above the 99th percentile) has been observed (Pinto et al. 2013). Piedmont is largely devoted to agriculture, and grape cultivation in particular; this region in fact produces some of the finest Italian red wines. More than 53000 ha of Piedmont are covered by vineyards, and they are mainly located in the plain and hilly areas (Biancotti et al. 2006). According to the results of a recent study (Acquaotta \& Fratianni 2013), the increasing rainfall intensity trend in these sectors could have a serious effect on this type of cultivation. For this reason, this work could be considered a novel contribution to the study of extreme events in Italy, as the studies developed so far in Italy and Piedmont have only considered a limited number of meteorological stations (Ciccarelli et al. 2008, Bodini \& Cossu 2010, Segoni et al. 2015), while we attempt here to provide a high-resolution analysis of extreme rainfall events throughout Piedmont. This is possible because rain gauges from 2 different meteorological monitoring networks are taken into account in order to obtain a high-density gauge network of stations spread over the whole study area. Furthermore, several studies have shown an increase in extreme events in the Mediterranean area in the last few years (Singh et al. 2013, Knapp et al. 2017), and these events have mainly been related to an increase in rainfall events, an extension of dry periods, and an increment in extreme wet and dry years. This study is an attempt, on the basis of the literature, to highlight the spatial and temporal distribution of extreme events in Piedmont (north-western Italy) over the period from January 2004 to December 2016.

The 2 main objectives of this study were:

- to make a climatic characterisation of Piedmont's plain and hilly zone, in order to quantify the spatial and temporal distribution of the annual and seasonal rainfall

- to analyse the spatial and temporal distribution of the current extreme rainfall events, and to identify the areas in Piedmont that are most affected by them

\section{DATA AND METHODS}

\subsection{Study area}

The area analysed in this work falls within the Piedmont region (north-western Italy). The region extends for $25402 \mathrm{~km}^{2}$ and is made up of 3 geomorphological areas: mountains (43\%), hills (30\%) and plains $(27 \%)$. The hilly area consists of the Turin, Langhe and Monferrato hills. The alpine mountain chain surrounds the region on 3 sides, and is located on the north-western border of Italy with France and 
Switzerland. The plain area is in the central sector. It is made up of the Po plain, and is crossed by the Po river and its several tributaries (Garzena et al. 2015). The study area analysed in this work is characterised by 2 of the 3 aforementioned geomorphological areas: plains and hills. The selected rain gauges are located between 300 and $700 \mathrm{~m}$ above sea level (a.s.l.). Two main types of factors determine the thermalpluviometric characteristics of Piedmont. The orography, which is the most important internal factor, controls Piedmont's climate, while the atmospheric circulation, with dry continental air flowing in from the Po Valley in the east and relatively moist Mediterranean and Atlantic air coming from the northwest, is the most important external factor (Fratianni et al. 2009, Giaccone et al. 2015). The annual distribution of precipitation in Piedmont is characterised by a bimodal trend, with 2 maxima (spring and autumn) and 2 minima (winter and summer). On the basis of the position of the main maximum, the secondary maximum and the main minimum, different types of pluviometric rates can be recognised in this area: a continental type, characterised by a main minimum in winter (prealpine, subcontinental and subalpine); and Mediterranean type, characterised by a main minimum in summer (subcoastal). Of these, 3 are continental (the main minimum in winter), while the fourth is Mediterranean (the main minimum in summer). network was started in 1988 and is characterised by 400 monitoring stations, with a density of 1 instrument every $100 \mathrm{~km}^{2}$. The instrumentation used consists of a tipping bucket rain gauge, CAE PMB2, with a $1000 \mathrm{~cm}^{2}$ diameter collector (Acquaotta et al. 2016)

- the agrometeorological network (RAM); this network has been active since the second half of the 1990s and is made up of 120 monitoring stations. These stations have been installed to support agricultural monitoring, and for this reason they are in the proximity of the main cultivation areas (e.g. vineyards, orchards). The RAM rainfall stations use a tipping-bucket SIAP UM7525 rain gauge with a $1000 \mathrm{~cm}^{2}$ diameter collector

The selected rain gauges (Fig. 1) are located between 300 and $700 \mathrm{~m}$ a.s.l. According to the elevation zonation model described by Beniston et al. (2011), this is the lowest zone, known as the planar zone. Therefore, the selected stations identify the plain and hilly homogeneous area in Piedmont, 90\% of which is located between 300 and $500 \mathrm{~m}$ a.s.l. Rainfall over $700 \mathrm{~m}$ was not analysed, because the distribution of rainfall is affected to a great extent by the elevation, and for this reason the mountain climate is more variable than the climate in the plains and hills, which are characterised by orographic uniformity (Meersmans et al. 2016). A period of study was identified, 1 January 2004 to 31 December 2016, that provided a complete and homogenous database. Since the selected series come from 2 different meteorological

\subsection{Dataset}

One of the main problems with rainfall measurement is the low representativeness of a large area. Moreover, the observations made by a single station are only representative of a restricted area in the neighbourhood of a rain gauge (Lanza \& Vuerich 2009, Mazza et al. 2014). For this reason, it is necessary to have a high density of rain gauges spread over the whole study area. Several networks, managed by public and local authorities, are available in Piedmont. In this study, the daily precipitation series of 2 independent automatic climate networks are analysed for the first time. These networks belong to:

- the Regional Agency for Environmental Protection (ARPA); this

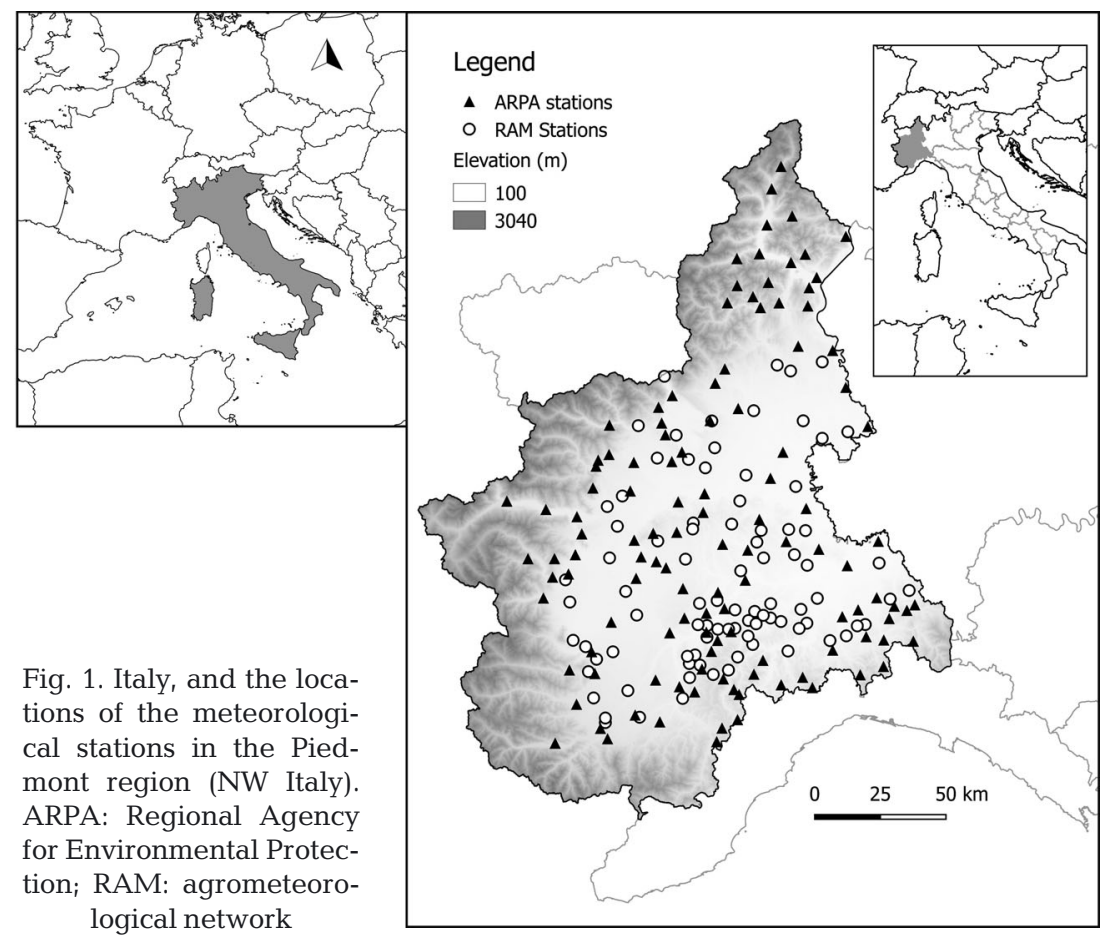


monitoring networks, it was necessary to verify whether they were comparable. The comparison was carried out using the free, open source script CoRain, which is written in R language (R Development Core Team 2011). This script uses an innovative analysis approach to compare 2 parallel rain series (with an overlapping period) (Guenzi et al. 2017) and is availed online (https://github.com/UniToDSTGruppo Clima/CoRain) under GNU GPL v3 license (Free Software Foundation 2007). After having confirmed the comparability of each of the selected meteorological stations, accurate historical research was carried out to evaluate the homogeneity of the series. This involved detecting any breaks caused by changes in location or in the instruments in the stations during their activity. The historical research was carried out by consulting the registers of the stations, where any replacements of an instrument or changes in position are reported. The stations with such known problems were removed from the dataset. Fortunately no breaks were identified by historical research. Subsequently, each series was submitted to a quality control. For this, all questionable values, such as daily precipitation amounts of less than zero, were deleted. In addition, any daily rainfall data outliers were identified and flagged. An example of an outlier is a weekly accumulation being transcribed as the value for 1 day. The flagged outliers were compared with precipitation series from neighbouring stations (Klein Tank et al. 2009). Moreover, daily precipitation values of $<1 \mathrm{~mm}$ in the series were deleted to prevent a set of small values that reflected changes in measuring precision from influencing the record (Wang et al. 2010). The obtained dataset was composed of 211 daily precipitation series measured in Piedmont from 1 January 2004 to 31 December 2016. In the first analysis carried out on the selected stations, the series showed continuity of the rainfall amounts over several years and $<10 \%$ gaps. The average amount of daily rainfall data available for each series was 4290 values, and the total dataset was therefore composed of 905000 values.

\subsection{Data analysis}

In this study, 211 daily precipitation series, recorded in Piedmont from 1 January 2004 to 31 December 2016, were analysed. Since rainfall offers a rather limited representativeness for large areas (Adhikary et al. 2015a), 2 geostatistical analyses were adopted: ordinary kriging and cluster analysis. First, considering the whole set of rain gauges, the annual precipitation data were spatialised on a regular $200 \times 200 \mathrm{~m}$ cell grid, which had the following vertices, expressed in WGS84 UTM-32N cartographic coordinates: North $5159500 \mathrm{~m} 4871500 \mathrm{~m}$ South, East $562500 \mathrm{~m} 304500 \mathrm{~m}$ West (Pai et al. 2014). Because the selected stations in this study are located between 300 and $700 \mathrm{~m}$, and elevation does not influence the rainfall distribution at this elevation, the spatial variation of precipitation was interpolated by means of the ordinary kriging method (Adhikary et al. 2015b, Ahmed et al. 2017), using the Automap package (Hiemstra \& Hiemstra 2013), which is based on R software. This geostatistical approach is a well established rainfall spatial interpolation method (StHilaire et al. 2003, Webster \& Oliver 2007). One advantage of kriging is its statistical manner, which improves the accuracy of estimates at grid points (Allard 2013). Once it was established that the rainfall was not homogeneously distributed in the study area, a cluster analysis (CA) was performed. CA is a statistical tool that is used extensively in climate studies to divide a study area into a limited number of homogeneous climate regions using, for example, rainfall data. Objects with the same features are classified in the same cluster, while dissimilar objects are assigned to different groups. Two types of clustering methods have been used in previous studies: hierarchical and non-hierarchical. The hierarchical method, which has been adopted in this study, is useful for a large volume of rainfall data (Ünal et al. 2003). Thus, different climatic areas were identified, based on the monthly rainfall amount, using Ward's method (Carvalho et al. 2016, Rau et al. 2017). This is an agglomerative technique where, starting from $\mathrm{N}$ clusters, the proximity matrix is calculated for the $\mathrm{N}$ clusters. In this matrix, the minimal distance between the clusters is measured and the 2 closest groups are combined. Once the matrix has been updated with the created cluster, this aggregation process is repeated until only 1 cluster remains (Iyigun et al. 2013). This method allows the optimum number of clusters to be identified through the depiction of a dendrogram, where the root represents a single cluster that contains all the data and the tops show each cluster generated by the partition (Türke et al. 2016). Climatic characterisation was then performed for each cluster, analysing the pluviometric regimes (Biancotti et al. 1998, 2005), the number of rainy days with rainfall $\geq 1 \mathrm{~mm}$, the annual average precipitation and the annual rainfall density.

Moreover, in order to have a better understanding of the extreme rainfall events that occur in different climatic regions, the climate indices, established by 
the Expert Team on Climate Change Detection Monitoring and Indices (ETCCDMI 2003), were calculated for each daily precipitation series. (Sillmann et al. 2013). The ClimPACT2 software package (Alexander et al. 2015) was used for each series, and the following indices were observed on an annual basis:

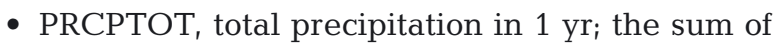
the precipitation amount measured in $\mathrm{mm}$

- CWD, consecutive wet days; the number of consecutive wet days with precipitation $\geq 1 \mathrm{~mm}$, measured in $\mathrm{d}$

- SDII, simple daily intensity index; the total annual rainfall divided by the number of rainy days, measured in $\mathrm{mm} \mathrm{d}^{-1}$ (Acquaotta \& Fratianni 2013, Skansi et al. 2013)

In order to establish the daily amount of rainfall that characterised each cluster, the thresholds by percentile were then calculated on a daily basis to identify the different precipitation types. The annual and seasonal percentiles of each cluster were calculated considering the daily series, and 4 classes of precipitation were established: weak, medium, heavy and very heavy (R95p) (Table 1) (Acquaotta et al. 2016). Once the daily thresholds had been identified, the annual and seasonal number of weak, medium, heavy and very heavy events that characterised each cluster was calculated. In order to compare the results obtained for each climatic area, the number of events was normalised, using the following equation: $S=n / d$, where $n$ is the number of recorded events and $d$ is the cluster dimension (number of stations). Finally, a statistical analysis was developed to evaluate the relationship between the normalised annual and seasonal number of event series of the 5 clusters. The parametric and nonparametric tests that were applied are:

- Student's $t$-test, which was used to evaluate whether each observed climatic area recorded the same mean of the normalised number of events

- the Kolmogorov-Smirnov test, which was adopted to evaluate whether the climatic areas had the same distribution for each rainfall class

Table 1. Names and ranges of the 4 precipitation classes, where $\mathrm{R}$ is the observed rainfall data

\begin{tabular}{|lc|}
\hline Class & Range \\
\hline Weak rain & $\mathrm{R}<50$ th \\
Medium rain & 50 th $\leq \mathrm{R}<$ 80th \\
Heavy rain & 80th $\leq \mathrm{R} \leq \mathrm{R} 95$ th \\
Very heavy rain (R95p) & $\mathrm{R}>95$ th \\
\hline
\end{tabular}

- the Wilcoxon rank sum test, which was applied to observe whether the clusters had the same population medians

A $p=5 \%$ significance level was used for all tests. The selected tests were fitted so that the null hypothesis (H0) was that the 2 compared means, distribution or median are equal, while the alternative hypothesis (H1) was that the true differences in means, median or distribution are not equal to 0 . If the $\mathrm{p}$-value was $>0.05$ the alternative hypothesis (H1) was rejected.

\section{RESULTS AND DISCUSSION}

In accordance with previous studies carried out by Acquaotta \& Fratianni (2013) and the Piedmont Region (Biancotti et al. 1998), the annual average rainfall is greater in the northern part of the region, with peaks $>1930 \mathrm{~mm} \mathrm{yr}^{-1}$ (recorded at Cicogna), while the driest area is the plain in the centre of Piedmont, with a total precipitation of $<800 \mathrm{~mm} \mathrm{yr}^{-1}$ (Fig. 2b). The spatial interpolation also revealed that 2014 was the wettest year during the 2004-2016 period, while 2007 was the driest. The comparison with the annual average rainfall distribution shows that not only was the northern part of Piedmont characterised by abundant precipitation in 2014, but all the stations located in the south, at the foothills of the Ligurian Apennines, were also affected. The annual precipitation recorded in 2014 in these sectors was between 2000 and $3000 \mathrm{~mm}$, much higher than the annual averages, which are between 1600 and $2300 \mathrm{~mm}$. Furthermore, a drier area characterised by the stations located in the central plain of Piedmont was also observed in 2014. Between 900 and $1100 \mathrm{~mm}$ of rainfall was recorded in this area, $100 \mathrm{~mm}$ higher than the annual average rainfall (Fig. 2c). In 2007 (Fig. 2a), the spatialisation indicated a dry sector that was not limited to the Piedmont plain, but also extended to the Monferrato hills, where 300 to $400 \mathrm{~mm}$ of rainfall was recorded, $300 \mathrm{~mm}$ below the annual average rainfall distribution. The precipitation recorded in 2007 gradually increased towards the north, but no sector was observed where the rainfall amount was much higher than the surrounding area. A maximum of $1600 \mathrm{~mm}$ was observed in this surrounding area, which is significantly lower than the $2300 \mathrm{~mm}$ recorded for the annual average rainfall distribution. The spatial distribution of rainfall was improved through the cluster analysis (Fig. 3). The application of this method highlighted 5 clusters, corresponding to 5 climatic zones in Piedmont. Table 2 shows that there are 3 particularly rainy areas. The wettest is 


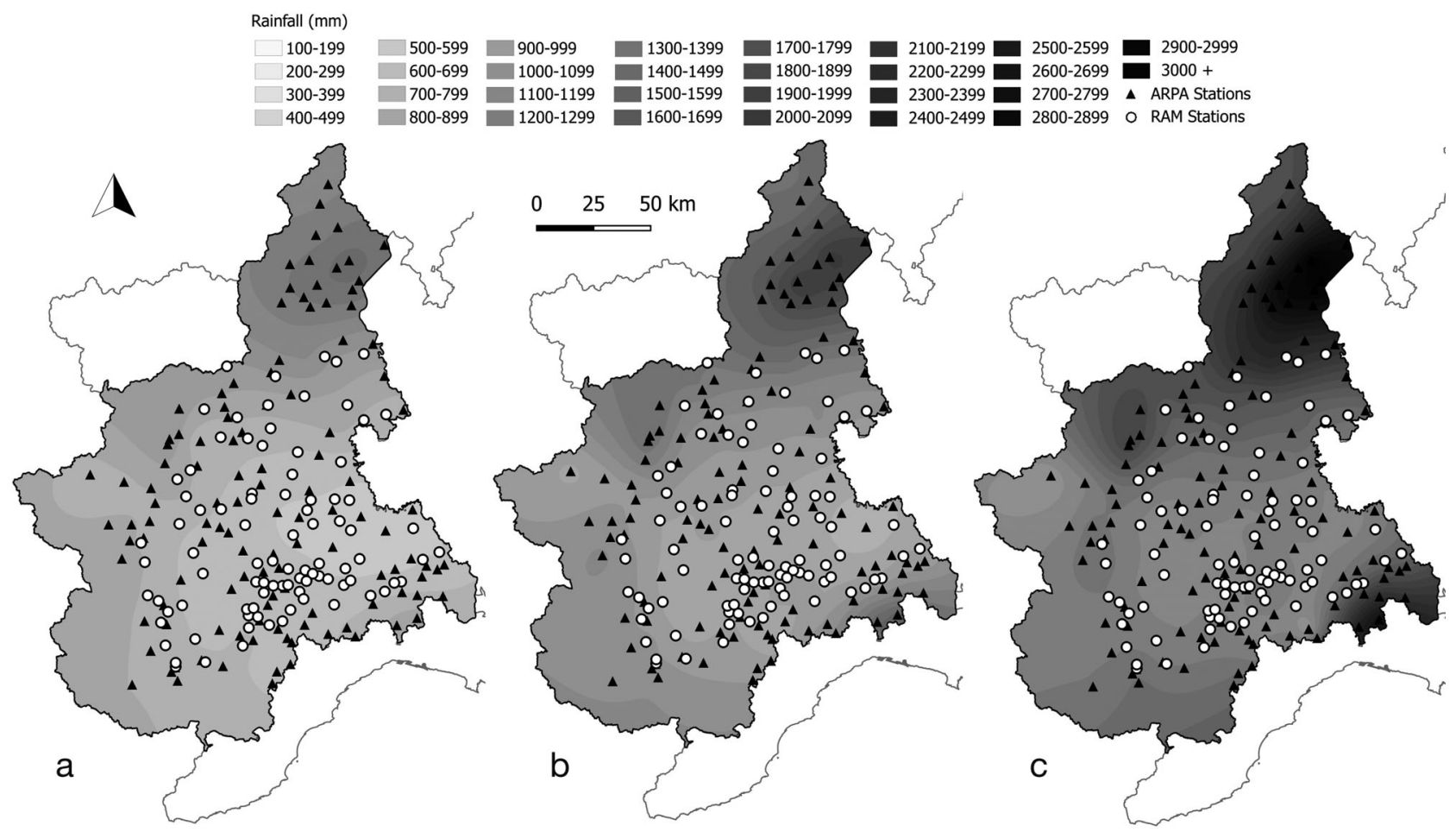

Fig. 2. Spatial distribution of rainfall in the Piedmont plains and hills for (a) the driest year (2007), (b) the study period (2004-2016) and (c) the rainiest year (2014). ARPA: Regional Agency for Environmental Protection, RAM: agrometeorological network

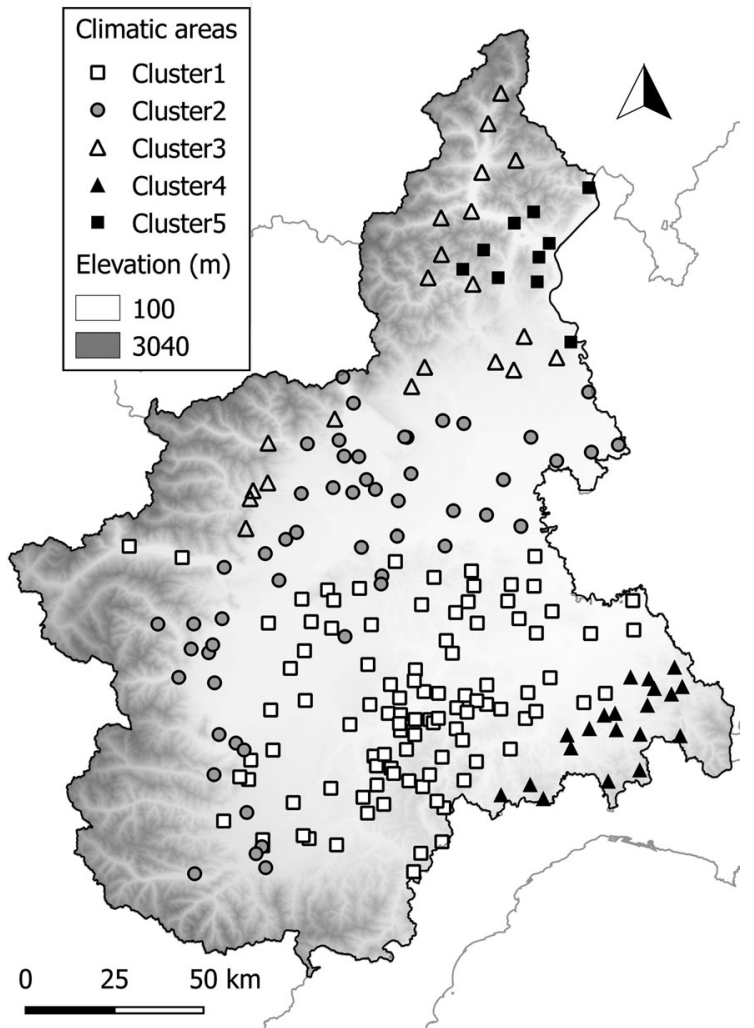

Fig. 3. Classification of rainfall into the 5 climatic regions that characterise the Piedmont region (NW Italy)
Cluster5, which includes the stations located in northern Piedmont. The annual rainfall is between 1699 and $1930 \mathrm{~mm}$, and the precipitation is more concentrated, with an average density of $19 \mathrm{~mm} \mathrm{~d}^{-1}$. The identified pluviometric regime is subalpine (maximum in autumn and spring, minimum in winter). The second wettest area is found in north-western Piedmont (Cluster3). The annual rainfall amounts are between 1500 and $1729 \mathrm{~mm}$. The average density of precipitation is $14 \mathrm{~mm} \mathrm{~d}^{-1}$, and the pluviometric regime is subalpine. The third area lies in the southeastern part of the region (Cluster4), at the foothills of the Ligurian Apennines. The rainfall in this area is between 677 and $1800 \mathrm{~mm}$. The average density is $12 \mathrm{~mm} \mathrm{~d}^{-1}$, and the pluviometric regime is sublittoral (maximum in autumn, minimum in winter). The 2 driest areas are in the central part of Piedmont (Table 2). The first is Cluster1, which is characterised by an annual rainfall of between 618 and $950 \mathrm{~mm}$. The average density is $11 \mathrm{~mm} \mathrm{~d}^{-1}$, and the pluviometric regime is subalpine. The second includes the rain gauges located at the foothills of the Maritime and Graie Alps (Cluster2), and the annual amount of rainfall is between 815 and $1170 \mathrm{~mm}$. The average density is $12 \mathrm{~mm} \mathrm{~d}^{-1}$, and the observed pluviometric regime is prealpine (maximum in spring and minimum in winter). 
Table 2. Maximum and minimum annual rainfall, density and seasonal rainfall distribution (pluviometric regime) recorded for each climatic region

\begin{tabular}{|c|c|c|c|c|}
\hline & \multicolumn{2}{|c|}{ Annual rainfall (mm) } & \multirow{2}{*}{$\begin{array}{c}\text { Density } \\
\left(\mathrm{mm} \mathrm{d}^{-1}\right)\end{array}$} & \multirow{2}{*}{$\begin{array}{l}\text { Pluviometric } \\
\text { regime }\end{array}$} \\
\hline & Max. & Min. & & \\
\hline Cluster1 & 950 & 618 & 11 & Subalpine \\
\hline Cluster2 & 1170 & 815 & 12 & Prealpine \\
\hline Cluster3 & 1729 & 1500 & 14 & Subalpine \\
\hline Cluster4 & 1800 & 677 & 12 & Sublittoral \\
\hline Cluster5 & 1930 & 1699 & 19 & Subalpine \\
\hline
\end{tabular}

Table 3. Annual study of the daily rainfall thresholds using the 95th, 80th and 50th percentiles for each climatic region

\begin{tabular}{|lccc|}
\hline & 95th $(\mathrm{mm})$ & 80th $(\mathrm{mm})$ & 50th $(\mathrm{mm})$ \\
\hline Cluster1 & 35.8 & 17.2 & 6.2 \\
Cluster2 & 40.4 & 18.8 & 6.6 \\
Cluster3 & 51.6 & 22.6 & 7.4 \\
Cluster4 & 41.2 & 18.0 & 6.2 \\
Cluster5 & 68.2 & 29.0 & 8.8 \\
\hline
\end{tabular}
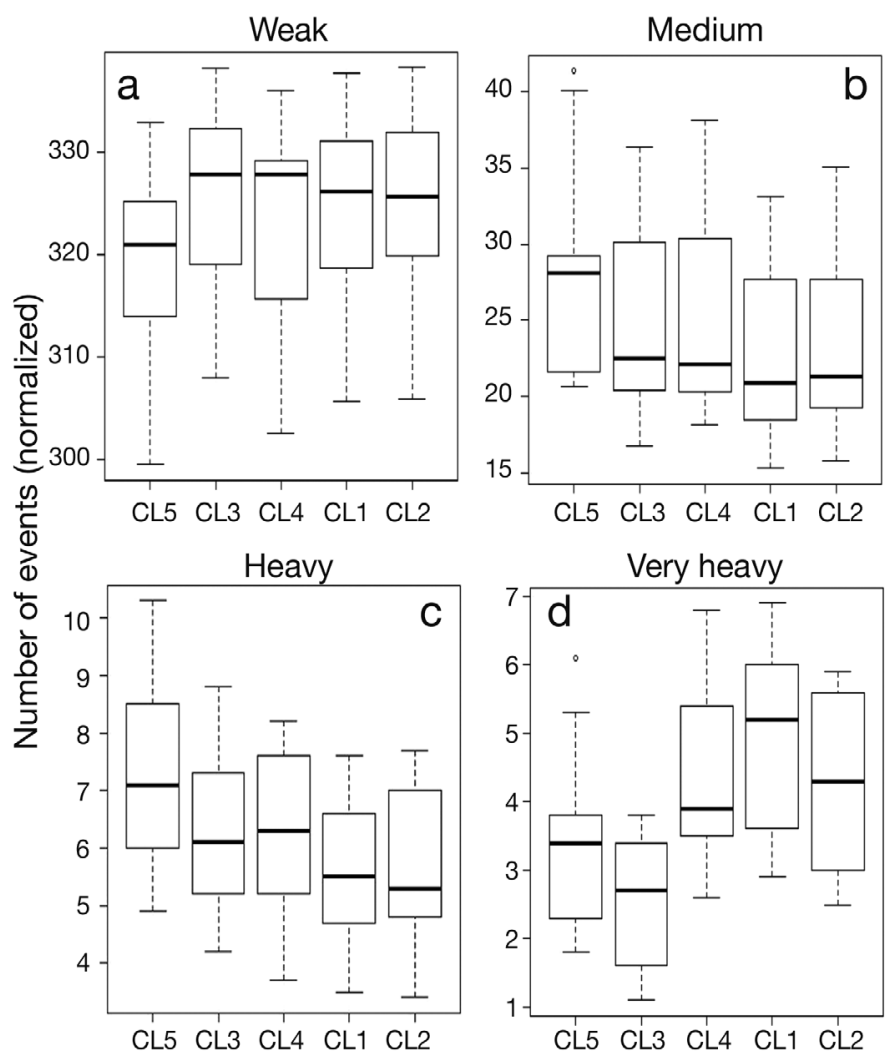

Fig. 4. The normalised annual number of rainfall events recorded in each climatic area for (a) weak events, (b) medium events, (c) heavy events and (d) very heavy events. Boxplots - midline: median; box: first and third quartiles; whiskers: maximum and minimum; circles: outliers
Compared with recent studies in northern Italy pertaining to the last few decades (Acquaotta \& Fratianni 2013, Pieri et al. 2016), the results obtained from the index highlight an annual rainfall increment (PRCPTOT). This increase is more notable in the north (Clus-

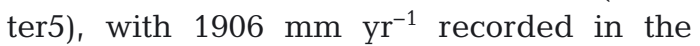
2004-2016 period, and $1489.2 \mathrm{~mm} \mathrm{yr}^{-1}$ for the reference period (Acquaotta \& Fratianni 2013). The value measured in central Piedmont (Cluster1) during the reference period

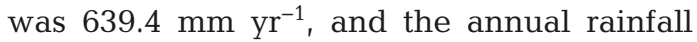
average in the 2004-2016 period was $760 \mathrm{~mm} \mathrm{yr}^{-1}$. Moreover, a growth in the average density (SDII) was observed over the whole study area. This increase in density was only $1 \mathrm{~mm} \mathrm{~d}^{-1}$ in the 2 driest clusters, while it was around $5 \mathrm{~mm} \mathrm{~d}^{-1}$ in the north. Furthermore, neither an increase nor a decrease was noted for the number of rainy days (CWD). In fact, in the central part of Piedmont, the value was about $66 \mathrm{~d}$ for both periods, while $100 \mathrm{~d}$ were recorded in the north. A comparison with other Italian sites shows that the precipitation trends show remarkable differences overall, depending on the local conditions. In fact, Tomozeiu et al. (2006) reported an absence of or uncertainties in trends in north-western Italy for the period they analysed (1958-2000), as did Toreti et al. (2009) for a similar period (1960-2006). Diodato (2007) observed a decrease in precipitation in southern Italy since the 17 th century, as did Liuzzo et al. (2016) during the period which started in 1910 and ended in 2010. As far as the central, western and eastern areas of the Mediterranean are concerned, Feidas et al. (2007) observed an annual decrease in rainfall for Greece for the 1955-2001 reference period, while Lorenzo-Lacruz et al. (2013) also observed a decrease in Spain during a similar period (1955-2005).

According to the spatial distribution, the annual rainfall classification shows that, for each precipitation type, the daily amounts were greater in Cluster5 than in Cluster1 or Cluster2 (Table 3). As far as weak rainfall is concerned, the box plot in Fig. 4a shows that the annual number of these recorded events was quite similar for each cluster, and was between 320 and $328 \mathrm{~d}$. The statistical analysis, in agreement with the box plot, demonstrates that all the clusters are correlated with each other; the p-values of the $t$-test and the Kolmogorov-Smirnov and Wilcoxon tests are all >0.05 (see Table 5). Table 4 shows that the daily amount for weak rainfall events in each season was similar for each period, and the box plots show that the recorded number of these events in all the seasons was analogous for all the clusters. As far as the 
Table 4. Seasonal study of the daily rainfall thresholds using the 95th, 80th and 50th percentiles for each climatic region

\begin{tabular}{|c|c|c|c|}
\hline & \multicolumn{3}{|c|}{ Daily rainfall threshold (mm) } \\
\hline & 95th & 80th & 50 th \\
\hline \multicolumn{4}{|l|}{ Cluster1 } \\
\hline Autumn & 45.4 & 20.8 & 7.6 \\
\hline Spring & 34.4 & 18.2 & 6.6 \\
\hline Summer & 33.6 & 15.4 & 5.6 \\
\hline Winter & 30.2 & 13.8 & 5.0 \\
\hline \multicolumn{4}{|l|}{ Cluster2 } \\
\hline Autumn & 52.2 & 22.8 & 8.2 \\
\hline Spring & 39.0 & 19.6 & 6.8 \\
\hline Summer & 37.0 & 16.6 & 5.8 \\
\hline Winter & 34.1 & 15.8 & 5.6 \\
\hline \multicolumn{4}{|l|}{ Cluster3 } \\
\hline Autumn & 70.2 & 28.2 & 9.0 \\
\hline Spring & 50.0 & 23.8 & 7.8 \\
\hline Summer & 45.0 & 19.4 & 6.8 \\
\hline Winter & 40.6 & 18.2 & 6.2 \\
\hline \multicolumn{4}{|l|}{ Cluster4 } \\
\hline Autumn & 57.8 & 22.1 & 7.4 \\
\hline Spring & 35.1 & 16.8 & 6.2 \\
\hline Summer & 33.4 & 16.6 & 5.6 \\
\hline Winter & 36.6 & 16.8 & 5.4 \\
\hline \multicolumn{4}{|l|}{ Cluster5 } \\
\hline Autumn & 92.6 & 40.8 & 10.8 \\
\hline Spring & 62.3 & 29.8 & 9.6 \\
\hline Summer & 62.2 & 25.2 & 7.6 \\
\hline Winter & 45.2 & 22.2 & 7.8 \\
\hline
\end{tabular}

medium (Fig. 4b) and heavy (Fig. 4c) rainfall events are concerned, the highest number of events was recorded in Cluster5. In fact, the annual number of medium precipitation events was 28 and was between 20 and 21 for the other clusters. The number of heavy events for Cluster 5 was 7 , while it was 5 for the other clusters. The number of heavy events for Cluster 5 was 28 and was between 20 and 21 for the other clusters. The statistical analysis shows that there is no correlation between Cluster5 and Cluster1, while the other clusters are related to each other as far as the median, the average and the distribution of the number of events are concerned (Table 5). The seasonal study shows that the highest daily threshold for the 80th percentile was recorded in autumn (Table 4) and, according to the distribution of the annual rainfall, it was greater in Cluster5 with $40.8 \mathrm{~mm} \mathrm{~d}^{-1}$. The box plots in Fig. 5 show that the medium and heavy events follow the annual distribution, while the statistical analysis reveals that Cluster5 is not correlated by the median, the average or the distribution of the number of events with the other clusters for medium events in summer. The heavy events in spring (Fig. 5) follow the annual statistic distribution, and there is no relationship between Cluster3 and Cluster1. This
Table 5. Annual p-values of the Student's $t$-test, and the Kolmogorov-Smirnov (KS) and Wilcoxon (W) tests for each rainfall class. A p $=5 \%$ significance level was used for all tests. In bold are p-values where the 2 compared series present a difference in means, median or distribution

\begin{tabular}{|c|c|c|c|c|}
\hline & \multicolumn{4}{|c|}{ Rainfall events } \\
\hline & Weak & Medium & Heavy & Very heavy \\
\hline$t$-test_CL5CL3 & 0.07 & 0.15 & 0.29 & 0.08 \\
\hline t-test_CL5CL4 & 0.29 & 0.16 & 0.32 & 0.06 \\
\hline t-test_CL5CL1 & 0.15 & 0.03 & 0.04 & 0.10 \\
\hline t-test_CL5CL2 & 0.12 & 0.15 & 0.29 & 0.11 \\
\hline t-test_CL3CL4 & 0.44 & 0.98 & 0.95 & $<0.001$ \\
\hline t-test_CL3CL1 & 0.71 & 0.38 & 0.42 & $<0.001$ \\
\hline$t$-test_CL3CL2 & 0.84 & 0.53 & 0.96 & $<0.001$ \\
\hline t-test_CL4CL1 & 0.70 & 0.37 & 0.38 & 0.48 \\
\hline t-test_CL4CL2 & 0.58 & 0.52 & 0.98 & 0.69 \\
\hline$t$-test_CL1CL2 & 0.87 & 0.80 & 0.36 & 0.27 \\
\hline KS test_CL5CL3 & 0.29 & 0.59 & 0.57 & 0.57 \\
\hline KS test_CL5CL4 & 0.57 & 0.30 & 0.57 & 0.29 \\
\hline KS test_CL5CL1 & 0.29 & 0.03 & 0.04 & 0.13 \\
\hline KS test_CL5CL2 & 0.57 & 0.30 & 0.57 & 0.13 \\
\hline KS test_CL3CL4 & 0.88 & 1.00 & 1.00 & 0.01 \\
\hline KS test_CL3CL1 & 1.00 & 0.59 & 0.88 & $<0.001$ \\
\hline KS test_CL3CL2 & 1.00 & 0.90 & 0.88 & 0.01 \\
\hline KS test_CL4CL1 & 0.88 & 0.90 & 0.88 & 0.88 \\
\hline KS test_CL4CL2 & 0.88 & 0.90 & 0.88 & 1.00 \\
\hline KS test_CL1CL2 & 1.00 & 0.90 & 0.13 & 0.57 \\
\hline W test_CL5CL3 & 0.29 & 0.59 & 0.57 & 0.57 \\
\hline W test_CL5CL4 & 0.57 & 0.30 & 0.57 & 0.29 \\
\hline W test_CL5CL1 & 0.29 & 0.03 & 0.03 & 0.13 \\
\hline W test_CL5CL2 & 0.57 & 0.30 & 0.57 & 0.13 \\
\hline W test_CL3CL4 & 0.88 & 1.00 & 1.00 & 0.01 \\
\hline W test_CL3CL1 & 1.00 & 0.59 & 0.88 & $<0.001$ \\
\hline W test_CL3CL2 & 1.00 & 0.90 & 0.88 & 0.01 \\
\hline W test_CL4CL1 & 0.88 & 0.90 & 0.88 & 0.88 \\
\hline W test_CL4CL2 & 0.88 & 0.90 & 0.88 & 1.00 \\
\hline W test_CL1CL2 & 1.00 & 0.90 & 0.13 & 0.57 \\
\hline
\end{tabular}

indicates that the 2 main rainiest clusters in spring are not correlated with the central area of Piedmont (Table 6). In fact, the main weather type in spring in north-western Italy, as observed by Nadal-Romero et al. (2014), is a perturbation from the north-east. This perturbation consists of low pressure over the Mediterranean area, and it affects the 2 sectors at the foothills of the western Alps in Piedmont. Finally, for very heavy events, the box plot (Fig. 4d) shows that, unlike the annual rainfall distribution, the highest number of these events was found in the driest sector (Cluster1). In fact, the annual number recorded in Cluster1 was 5, and was around 3 in Cluster5 and Cluster3. The statistical analysis, in agreement with what can be observed in the box plot (Fig. 4d), shows that there is a relationship between Cluster4, Cluster2 and Cluster1, while Cluster3 is not related to the central sector or to the southern one (Table 5). These high rates of very heavy rainfall in the central Pied- 

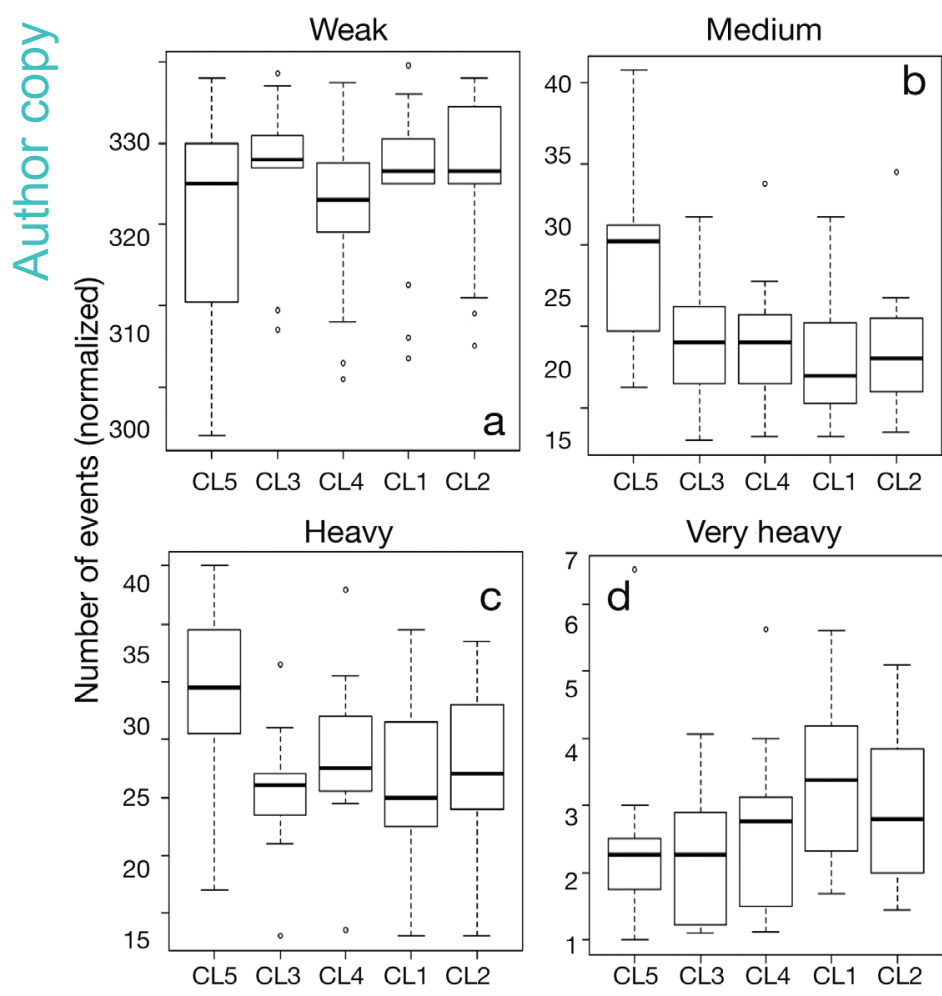

Fig. 5. The normalised seasonal number of rainfall events recorded in each climatic area for (a) autumn weak events, (b) summer medium events, (c) spring heavy events and (d) autumn very heavy events. Boxplots as in Fig. 4

mont area are the main climatic characteristic that make several crops, in particular grapes, vulnerable to erosion (Poesen \& Hooke 1997). Several studies (Morvan et al. 2014, Biddoccu et al. 2016) have demonstrated that the vineyards in north-western Italy are located in the regions that have incurred the highest soil loss, which has been estimated as being between 47 and $70 \mathrm{t} \mathrm{ha}^{-1} \mathrm{yr}^{-1}$ (Rodrigo Comino et al. 2015). This study has indicated that the rainiest season is autumn, and Table 4 shows that the highest daily amount was also recorded in this period. In fact, the very heavy rainfall in Cluster5 is much higher than that of the other groups. This area is in fact characterised by $92.6 \mathrm{~mm} \mathrm{~d}^{-1}$, in contrast with the $52.2 \mathrm{~mm} \mathrm{~d}^{-1}$ for Cluster2 and $45.4 \mathrm{~mm} \mathrm{~d}^{-1}$ for Cluster1. The box plots (Fig. 5d) show that the highest number of extreme events was recorded in autumn, and like the annual distribution, they are more abundant in the driest sectors. In this regard, the statistical analysis confirms this pattern; in fact, statistically significant p-values can be observed for Cluster1 and Cluster2, but not for Cluster5. This distribution of extreme events, especially during autumn, makes the central Piedmont sector very vulnerable to erosion
(Martínez Casasnovas et al. 2016). This area is largely devoted to wine production, and Biddoccu et al. (2016) observed the highest soil erosion rates in young vineyards in autumn, in particular during the months of September and October, due to the increase in the footprints of the wine growers. Rodrigo Comino et al. (2015) recorded high infiltration rates (almost $100 \%$ ) and subsurface flows during very heavy events in this period. National and international studies of recorded extreme events have led to contrasting results. A general increase in the number of extreme events along the Mediterranean coast was reported by De Luis et al. (2009) for the second half of the 20th century, as well as by Acquaotta et al. (in press), who observed that recent extreme rainfall events have affected Liguria (NW Italy), and by Fernández-Montes \& Rodrigo (2015), for the 19702007 period in the south-eastern Iberian Peninsula. Terzago et al. (2013), Fratianni et al. (2015) and Morán-Tejeda et al. (2016) detected an increase in the rain-on-snow precipitation amount for the $50 \mathrm{yr}$ period of 1961-2010. Rodrigo (2010) reported a constant or decreasing number of extreme events, mainly in winter and spring, in inland areas during the second half of the 20th century. These differences could be due to the diverse microclimate and topography of the investigated sites. The changes in climate variability in the Mediterranean areas have been more pronounced, starting from 1980 (Pieri et al. 2016), probably as a result of the strengthening of the North Atlantic Oscillation (Lolis \& Türke 2016).

\section{CONCLUSION}

In this study, we have characterised the spatial and temporal distribution of rainfall in Piedmont using a multivariate methodology. The analysis has highlighted an increase in precipitation, which is more marked in the north than in the central drier area. This, linked with the intensification of rainfall density and the constant number of rainy days, suggests that each single rainfall event in Piedmont in the 20042016 period was characterised by a higher rainfall amount than in the past. An innovative approach has been adopted in the detailed study of extreme events reported in this paper to classify these events over an extended area, such as Piedmont, using rainfall thresholds. This approach has in fact demonstrated that the distribution of rainfall, classified as wet, medium and heavy, is in agreement with the annual rainfall distribution. As far as heavy events are concerned, this methodology has shown that even 


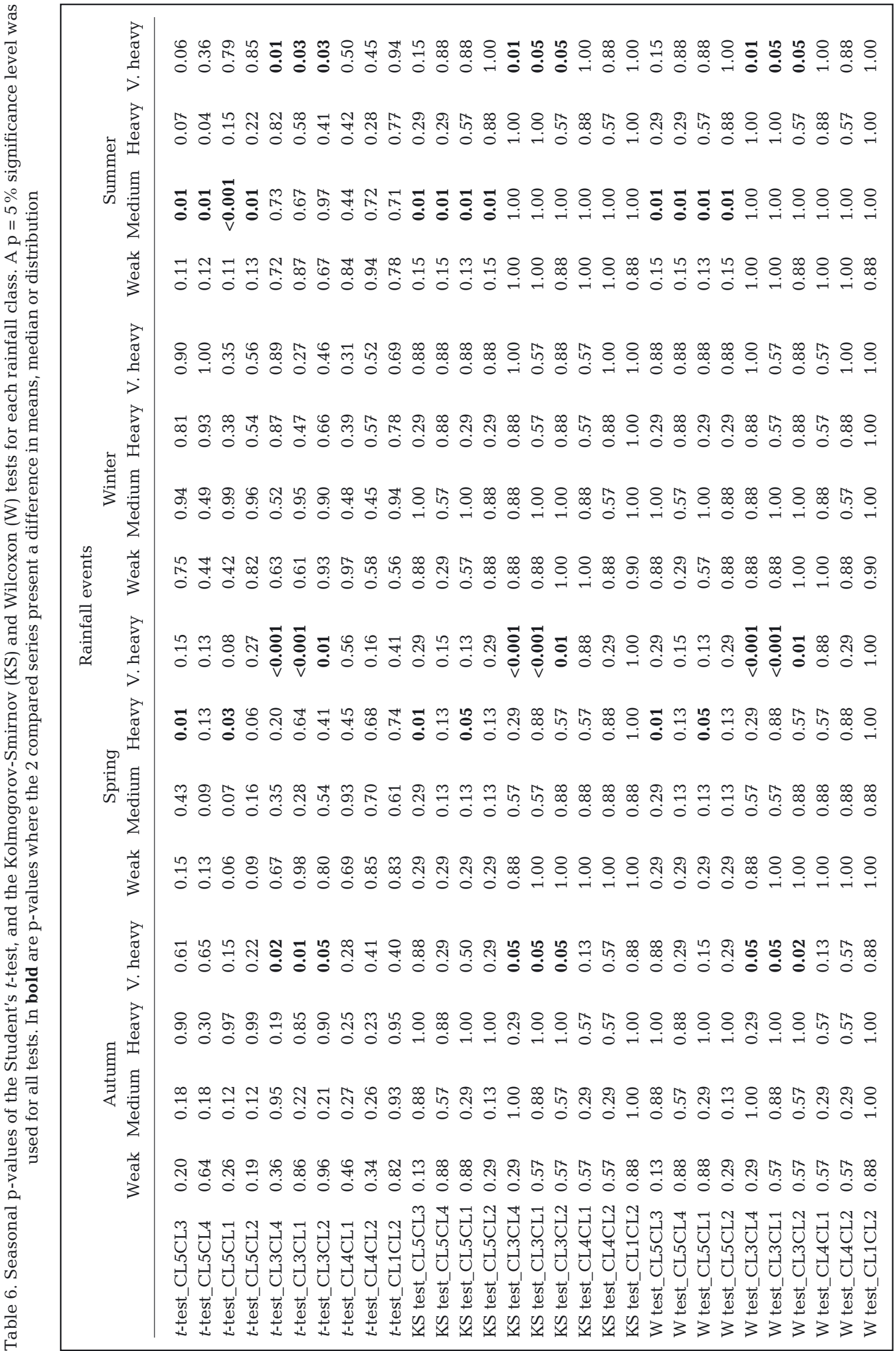


though the northern sector is the wettest, central Piedmont is the area where the highest number of extreme events has been recorded. Finally, this study may contribute to a better understanding of the dynamics between extreme wet events and spatial distribution in the Piedmont region, and of the possible impacts on ecosystems. Cortesi et al. (2012) have shown that precipitation is one of the main factors in the process of creating landscape and, in this context, different temporal and spatial distributions of extreme rainfall events can lead to various climatic conditions that can affect the landscape process, and can thus have an impact on natural and social processes, such as floods, soil erosion, cultivation and water arability.

Acknowledgements. The authors thank Federico Spanna of Regione Piemonte and Simone Falzoi of the University of Turin for the RAM database. Thanks are also due to ARPA Piemonte, in particular to the Dipartimento Sistemi Previsionali - Struttura Semplice 'Meteorologia e Clima', for the ARPA database. Finally, thanks to the reviewer for the comments that have improved the quality of the manuscript.

\section{LITERATURE CITED}

Acquaotta F, Fratianni S (2013) Analysis on long precipitation series in Piedmont (North-West Italy). Am J Clim Change 2:14-24

Acquaotta F, Fratianni S, Venema V (2016) Assessment of parallel precipitation measurements networks in Piedmont, Italy. Int J Climatol 36:3963-3974

Acquaotta F, Faccini F, Fratianni S, Paliaga G, Sacchini A (in press) Rainfall intensity in Genoa Metropolitan Area (Northern Mediterranean): secular variations and consequences. Weather, doi:10.1002/wea.3208

Adhikary SK, Yilmaz AG, Muttil N (2015a) Optimal design of rain gauge network in the Middle Yarra River catchment, Australia. Hydrol Processes 29:2582-2599

Adhikary SK, Yilmaz AG, Muttil N (2015b) Improved spatial interpolation of rainfall using Genetic Programming. 21st Int Congr Modelling and Simulation, Gold Coast, 29 Nov to 4 Dec 2015, p 2214-2220

Ahmed K, Shahid S, Chung ES, Ismail T, Wang XJ (2017) Spatial distribution of secular trends in annual and seasonal precipitation over Pakistan. Clim Res 74:95-107

Alexander L, Yang H, Perkins S (2015) ClimPACT. Indices and software. Available online at www.wmo.int/pages/ $\mathrm{prog} / \mathrm{wcp} / \mathrm{ccl} /$ opace/opace4/meetings/documents/ETCR SCI_software_documentation_v2a.doc (accessed on 20 March 2017)

Allard D (2013) Book-review — J-P Chilès, P Delfiner: Geostatistics: modeling spatial uncertainty. Math Geosci 45: $377-380$

Alpert P, Ben Gai T, Baharad A, Benjamini Y and others (2002) The paradoxical increase of Mediterranean extreme daily rainfall in spite of decrease in total values. Geophys Res Lett 29:1-4

Beniston M, Uhlmann B, Goyette S, Lopez-Moreno JI (2011) Will snow-abundant winters still exist in the Swiss Alps in an enhanced greenhouse climate? Int J Climatol 31: $1257-1263$
Biancotti A, Bellardone G, Bovo S, Cagnazzi B, Giacomelli L, Marchisio C (1998) Distribuzione regionale di piogge e temperature. Studi climatologici in Piemonte, Vol 1. Regione Piemonte \& Università degli Studi di Torino, Torino

Biancotti A, Destefanis E, Fratianni S, Masciocco L (2005) On precipitation and hydrology of Susa Valley (western Alps). Geogr Fis Din Quat 7:51-58

Biancotti A, Fazzini M, Fratianni S (2006) Climate and terroir in two different areas of the Italian Alps: Susa Valley (Piemonte) and Adige Valley (Trentino). Boll Soc Geol Ital 6:211-219

Biddoccu M, Ferraris S, Opsi F, Cavallo E (2016) Long-term monitoring of soil management effects on runoff and soil erosion in sloping vineyards in Alto Monferrato (NorthWest Italy). Soil Tillage Res 155:176-189

Boccolari M, Malmusi S (2013) Changes in temperature and precipitation extremes observed in Modena, Italy. Atmos Res 122:16-31

* Bodini A, Cossu QA (2010) Vulnerability assessment of Central-East Sardinia (Italy) to extreme rainfall events. Nat Hazards Earth Syst Sci 10:61-72

Brunetti M, Buffoni L, Mangianti F, Maugeri M, Nanni T (2004) Temperature precipitation and extreme events during the last century in Italy. Global Planet Change 40: 141-149

Carvalho MJ, Melo-Gonçalves P, Teixeira JC, Rocha A (2016) Regionalization of Europe based on a $K$-Means Cluster Analysis of the climate change of temperatures and precipitation. Phys Chem Earth Parts ABC 94:22-28

* Ciccarelli N, Von Hardenberg J, Provenzale A, Ronchi C, Vargiu A, Pelosini R (2008) Climate variability in northwestern Italy during the second half of the 20th century. Global Planet Change 63:185-195

Cortesi N, González-Hidalgo JC, Brunetti M, Martin-Vide J (2012) Daily precipitation concentration across Europe 1971-2010. Nat Hazards Earth Syst Sci 12:2799-2810

* Davis CJ, Hanna EG (2016) Temperature and rainfall trends in northern Australia 1911-2013: implications for human activity and regional development. Clim Res 71:1-16

*De Luis M, González Hidalgo JC, Longares LA, Štepánek P (2009) Seasonal precipitation trends in the Mediterranean Iberian Peninsula in second half of 20th century. Int J Climatol 29:1312-1323

* Diodato N (2007) Climatic fluctuations in southern Italy since the 17th century: reconstruction with precipitation records at Benevento. Clim Change 80:411-431

* Drobinski P, Silva ND, Panthou G, Bastin S and others (2016) Scaling precipitation extremes with temperature in the Mediterranean: past climate assessment and projection in anthropogenic scenarios. Clim Dyn, doi:10.1007/ s00382-016-3083-x

ETCCDMI (Expert Team for Climate Change Detection Monitoring and Indices) (2003) CCI/CLIVAR first team meeting report, 24-26 November 2003. Zuckerman Institute/Climatic Research Unit, University of East Anglia, Norwich

Fazzini M, Fratianni S, Biancotti A, Billi P (2004) Skiability conditions in several skiing complexes on Piedmontese and Dolomitic alps. Meteorol Z 13:253-258

Feidas H, Noulopoulou C, Makrogiannis T, Bora-Senta E (2007) Trend analysis of precipitation time series in Greece and their relationship with circulation using surface and satellite data: 1955-2001. Theor Appl Climatol 87:155-177

*Fernández-Montes S, Rodrigo FS (2015) Trends in surface air temperatures, precipitation and combined indices in 
the southeastern Iberian Peninsula (1970-2007). Clim Res 63:43-60

Fratianni S, Cassardo C, Cremonini R (2009) Climatic characterization of foehn episodes in Piedmont Italy. Geogr Fis Din Quat 32:15-22

Fratianni S, Terzago S, Acquaotta F, Faletto M, Garzena D, Prola MC, Barbero S (2015) How snow and its physical properties change in a changing climate alpine context? In: Lollino G, Manconi A, Clague J, Shan W, Chiarle M (eds) Engineering geology for society and territory, Vol 1. Springer, Cham, p 57-60

Free Software Foundation (2007) GNU general public license (GPL v3). Available online at www.gnu.org/ licenses/gpl.html (accessed 1 June 2017)

Garzena D, Fratianni S, Acquaotta F (2015) Temperature analysis on the north-western Italian alps through the use of satellite images and ground-based meteorological stations. In: Lollino G, Manconi A, Clague J, Shan W, Chiarle $M$ (eds) Engineering geology for society and territory, Vol 1. Springer, Cham, p 77-80

Giaccone E, Colombo N, Acquaotta F, Paro L, Fratianni S (2015) Climate variations in a high altitude Alpine basin and their effects on a glacial environment (Italian Western Alps). Atmósfera 28:117-128

Guenzi D, Acquaotta F, Garzena D, Fratianni S (2017) CoRain: A free and open source software for rain series comparison. Earth Sci Inform 10:405-416

Haylock MR, Peterson TC, Alves LM, Ambrizzi T, Anunciação YMT, Baez J, Corradi V (2006) Trends in total and extreme South American rainfall in 1960-2000 and links with sea surface temperature. J Clim 19:1490-1512

Hiemstra P, Hiemstra MP (2013) Package 'automap'. Compare 105:10

IPCC (2013) Summary for policymakers. In: Stocker TF, Qin D, Plattner GK, Tignor M and others (eds) Climate change 2013: the physical science basis. Contribution of Working Group I to the Fifth Assessment Report of the Intergovernmental Panel on Climate Change. Cambridge University Press, Cambridge and New York, NY, p $1-30$

IPCC (2014a) Synthesis report. In: Core Writing Team, Pachauri RK, Meyer LA (eds) Climate Change 2014. Contribution of Working Groups I, II and III to the Fifth Assessment Report of the Intergovernmental Panel on Climate Change. IPCC, Geneva

IPCC (2014b) Climate change 2014: impacts adaptation and vulnerability. Part A. Global and sectoral aspects. Field CB, Barros VR, Dokken DJ, Mach KJ, and others (eds) Contribution of Working Group II to the Fifth Assessment Report of the Intergovernmental Panel on Climate Change. Cambridge University Press, Cambridge

Iwashima T, Yamamoto R (1993) A statistical analysis of the extreme events: long-term trend of heavy daily precipitation. J Meteorol Soc Jpn 71:637-640

Iyigun C, Türkeş M, Batmaz I, Yozgatligil C, Purutçuoğlu V, Koç EK, Öztürk MZ (2013) Clustering current climate regions of Turkey by using a multivariate statistical method. Theor Appl Climatol 114:95-106

Kharin VV, Zwiers FW, Zhang X, Wehner M (2013) Changes in temperature and precipitation extremes in the CMIP5 ensemble. Clim Change 119:345-357

Klein Tank AMG, Zwiers FW, Zhang X (2009) Guidelines on analysis of extremes in a changing climate in support of informed decisions for adaptation. Climate data and monitoring, WCDMP-No 72. WMO-TD No 1500. WMO, Geneva

Knapp AK, Avolio ML, Beier C, Carroll CJ, Collins SL,
Dukes JS, Loik ME (2017) Pushing precipitation to the extremes in distributed experiments: recommendations for simulating wet and dry years. Glob Chang Biol 23: 1774-1782

K Lanza LG, Vuerich E (2009) The WMO field intercomparison of rain intensity gauges. J Geophys Res Atmos 94: $534-543$

KLiuzzo L, Bono E, Sammartano V, Freni G (2016) Analysis of spatial and temporal rainfall trends in Sicily during the 1921-2012 period. Theor Appl Climatol 126:113-129

* Lolis CJ, Türkeş M (2016) Atmospheric circulation characteristics favouring extreme precipitation in Turkey. Clim Res 71:139-153

Lopes RH (2011) Kolmogorov-Smirnov test. In: Lovric M (ed) International Encyclopedia of Statistical Science, Vol 1. Springer, Berlin, p 718-720

Lorenzo-Lacruz J, Vicente-Serrano SM, González-Hidalgo JC, López-Moreno JI, Cortesi N (2013) Hydrological drought response to meteorological drought in the Iberian Peninsula. Clim Res 58:117-131

* Martínez Casasnovas JA, Ramos MC, Benites G (2016) Soil and water assessment tool soil loss simulation at the sub basin scale in the Alt Penedès-Anoia vineyard region (NE Spain) in the 2000s. Land Degrad Dev 27: 160-170

Mazza A, Antonini A, Melani S, Ortolani A (2014) Estimates of cumulative rainfall over a large area by weather radar. Proc SPIE 9242, Remote Sensing of Clouds and the Atmosphere $\mathrm{XIX}_{i}$ and Optics in Atmospheric Propagation and Adaptive Systems XVII, 17 October 2014, 92420V

Meersmans J, Van Weverberg K, De Baets S, De Ridder F, Palmer SJ, van Wesemael B, Quine TA (2016) Mapping mean total annual precipitation in Belgium by investigating the scale of topographic control at the regional scale. J Hydrol (Amst) 540:96-105

*Morán-Tejeda E, López Moreno JI, Stoffel M, Beniston M (2016) Rain-on-snow events in Switzerland: recent observations and projections for the 21st century. Clim Res 71: $111-125$

Korvan X, Naisse C, Malam Issa O, Desprats JF, Combaud A, Cerdan O (2014) Effect of ground cover type on surface runoff and subsequent soil erosion in Champagne vineyards in France. Soil Use Manage 30:372-381

*Nadal-Romero E, Cortesi N, González-Hidalgo JC (2014) Weather types, runoff and sediment yield in a Mediterranean mountain landscape. Earth Surf Proc Land 39: $427-437$

* Nolan P, O'Sullivan J, McGrath R (2017) Impacts of climate change on mid twenty first century rainfall in Ireland: a high resolution regional climate model ensemble approach. Int J Climatol 37:4347-4363

Pai DS, Sridhar L, Rajeevan M, Sreejith OP, Satbhai NS, Mukhopadhyay B (2014) Development of a new high spatial resolution $\left(0.25^{\circ} \times 0.25^{\circ}\right)$ long period $(1901-2010)$ daily gridded rainfall data set over India and its comparison with existing data sets over the region. Mausam (New Delhi) 65:1-18

*Piccarreta M, Pasini A, Capolongo D, Lazzari M (2013) Changes in daily precipitation extremes in the Mediterranean from 1951 to 2010: the Basilicata region, southern Italy. Int J Climatol 33:3229-3248

* Pieri L, Rondini D, Ventura F (2016) Changes in the rainfall-streamflow regimes related to climate change in a small catchment in Northern Italy. Theor Appl Climatol 129:1075-1087

Pinto JG, Ulbrich S, Parodi A, Rudari R, Boni G, Ulbrich U 
(2013) Identification and ranking of extraordinary rainfall events over Northwest Italy: the role of Atlantic moisture. J Geophys Res Atmos 118:2085-2097

Foesen JW, Hooke JM (1997) Erosion flooding and channel management in Mediterranean environments of southern Europe. Prog Phys Geogr 21:157-199

* Queralt S, Hernández E, Barriopedro D, Gallego D, Ribera P, Casanova C (2009) North Atlantic Oscillation influence and weather types associated with winter total and extreme precipitation events in Spain. J Geophys Res Atmos 94:675-683

R Development Core Team (2011) R: a language and environment for statistical computing. R Foundation for Statistical Computing, Vienna Available online at www.rproject.org/ (accessed 1 June 2017)

Rau P, Bourrel L, Labat D, Melo P, Dewitte B, Frappart F, Felipe O (2017) Regionalization of rainfall over the Peruvian Pacific slope and coast. Int J Climatol 37:143-158

Rodrigo FS (2010) Changes in the probability of extreme daily precipitation observed from 1951 to 2002 in the Iberian Peninsula. Int J Climatol 30:1512-1525

Rodrigo Comino J, Brings C, Lassu T, Iserloh T and others (2015) Rainfall and human activity impacts on soil losses and rill erosion in vineyards (Ruwer Valley, Germany). Solid Earth 6:823-837

Romero R, Guijarro JA, Ramis C, Alonso S (1998) A 30-year (1964-1993) daily rainfall data base for the Spanish Mediterranean regions: first exploratory study. Int J Climatol 18:541-560

Russo A, Trigo RM, Martins H, Mendes MT (2014) $\mathrm{NO}_{2}$, PM10 and $\mathrm{O}_{3}$ urban concentrations and its association with circulation weather types in Portugal. Atmos Environ 89: 768-785

Scherrer SC, Begert M, Croci Maspoli M, Appenzeller C (2016) Long series of Swiss seasonal precipitation: regionalization trends and influence of large scale flow. Int J Climatol 36:3673-3689

Segoni S, Lagomarsino D, Fanti R, Moretti S, Casagli N (2015) Integration of rainfall thresholds and susceptibility maps in the Emilia Romagna (Italy) regional-scale landslide warning system. Landslides 12:773-785

Sillmann J, Kharin VV, Zwiers FW, Zhang X, Bronaugh D (2013) Climate extremes indices in the CMIP5 multimodel ensemble. 2. Future climate projections. J Geophys Res Atmos 118:2473-2493

Singh D, Tsiang M, Rajaratnam B, Diffenbaugh NS (2013) Precipitation extremes over the continental United States in a transient high-resolution ensemble climate model experiment. J Geophys Res Atmos 118:7063-7086

Skansi MM, Brunet M, Sigró J, Aguilar E, Groening JAA, Bentancur OJ, Rojas CO (2013) Warming and wetting signals emerging from analysis of changes in climate

Editorial responsibility: Gerrit Hoogenboom, Gainesville, Florida, USA extreme indices over South America. Global Planet Change 100:295-307

St-Hilaire A, Ouarda TB, Lachance M, Bobée B, Gaudet J, Gignac C (2003) Assessment of the impact of meteorological network density on the estimation of basin precipitation and runoff: a case study. Hydrol Processes 17: 3561-3580

Terzago S, Fratianni S, Cremonini R (2013) Winter precipitation in Western Italian Alps (1926-2010). Meteorol Atmos Phys 119:125-136

* Tomozeiu R, Pavan V, Cacciamani C, Amici M (2006) Observed temperature changes in Emilia-Romagna: mean values and extremes. Clim Res 31:217-225

Toreti A, Fioravanti G, Perconti W, Desiato F (2009) Annual and seasonal precipitation over Italy from 1961 to 2006. Int J Climatol 29:1976-1987

Türkeş M, Yozgatlıgil C, Batmaz İ, Iyigün C, Kartal Koç E, Fahmi FM, Aslan S (2016) Has the climate been changing in Turkey? Regional climate change signals based on a comparative statistical analysis of two consecutive time periods, 1950-1980 and 1981-2010. Clim Res 70: $77-93$

Ünal Y, Kindap T, Karaca M (2003) Redefining the climate zones of Turkey using cluster analysis. Int J Climatol 23: 1045-1055

Vicente Serrano SM, Beguería S, López Moreno JI, García Vera MA, Stepanek P (2010) A complete daily precipitation database for northeast Spain: reconstruction, quality control, and homogeneity. Int J Climatol 30: 1146-1163

*Wang XL, Wen $\mathrm{QH}, \mathrm{Wu}$ Y (2007) Penalized maximal $t$ test for detecting undocumented mean change in climate data series. J Appl Meteorol Climatol 46:916-931

*Wang XL, Chen H, Wu Y, Feng Y, Pu Q (2010) New techniques for the detection and adjustment of shifts in daily precipitation data series. J Appl Meteorol Climatol 49: 2416-2436

Webster R, Oliver MA (2007) Geostatistics for environmental scientists, 2nd edn. John Wiley \& Sons, Chichester

Wilcox R (2005) Kolmogorov-Smirnov test. In: Armitage P, Colton T (eds) Encyclopedia of Biostatistics, 2nd edn. John Wiley \& Sons, Hoboken

Xoplaki E, Luterbacher J, Burkard R, Patrikas I, Maheras P (2000) Connection between the large-scale $500 \mathrm{hPa}$ geopotential height fields and precipitation over Greece during wintertime. Clim Res 14:129-146

Kandonadi L, Acquaotta F, Fratianni S, Zavattini JA (2016) Changes in precipitation extremes in Brazil (Paraná River basin). Theor Appl Climatol 123:741-756

Z Zhang X, Hogg WD, Mekis É (2001) Spatial and temporal characteristics of heavy precipitation events over Canada. J Clim 14:1923-1936

Submitted: October 4, 2017; Accepted: May 4, 2018 Proofs received from author(s): July 18, 2018 